engineering, shipbuilding and marine engineering, and the woollen and worsted trades accounted in the aggregate for a decline of 200,000 persons. The only important export industries to show substantial increases were the electrical trades ( 27 per cent.), the motor industry (21 per cent.), and artificial silk (48 per cent.), all comparatively new and progressive branches of production. Among non-export industries which have shown a high rate of expansion are the distributive trades (25 per cent.) and the building and furnishing trades (19 per cent.). That the old established exporting industries have not kept pace with other trades is borne out by statistics of unemployment. Between 1923 and 1927 the percentage of unemployment averaged 13.5 per cent. in the exporting group, and only $\mathbf{9 \cdot 2}$ in other insured industries.

\section{Geographical Redistribution.}

The migration of industry from the northern to the southern counties of England is perhaps the most interesting development in post-War Britain. The tendency has been noted by a number of observers, but it does not seem to have received the attention which it deserves. The Committee on Trade and Industry points out that in July 1923 the insured persons were divided between the southern and northern sections of the country in the proportion $45 \cdot 7$ (south) to $54 \cdot 3$ (north). In 1927 the proportion in the south had increased to 47 and in the north had declined to 53. Still more striking figures are obtained when smaller areas are examined, as will be seen from the following table:

Percentage Increase, 1923-27, in the Number of Insured Persons.

\begin{tabular}{|c|c|c|c|c|}
\hline & $7 \cdot 29$ & Midlands & 6.03 & Wales \\
\hline $\begin{array}{l}\text { South-Eastern } \\
\text { South-Wester }\end{array}$ & $\begin{array}{r}15 \cdot 83 \\
8 \cdot 60\end{array}$ & $\begin{array}{l}\text { North-Eastern } \\
\text { North-Wester }\end{array}$ & $\begin{array}{l}3 \cdot 09 \\
3.73\end{array}$ & $\begin{array}{l}\text { Scotland } \\
\text { N. Ireland }\end{array}$ \\
\hline
\end{tabular}

The figures for unemployment tell the same tale of greater economic activity in the south than in the north.
Percentage Unemployed (Mid-Year).

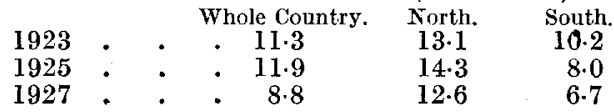

Statistics show that certain industries, for example, stove, grate, pipe, and general iron founding, glue, soap, ink, match, and carpet manufacture, have expanded in the south but have declined in the north. Other trades, such as constructional engineering, bleaching, dyeing, furniture making, motor vehicle construction, silk, electrical engineering, etc., have increased more rapidly in the south than in the north. Even the steel industry has shifted southwards, Lincolnshire and the Midlands having increased their steel production by 700,000 tons, while on the east coast and in Scotland output declined 500,000 tons. The coke industry has tended to follow the movement of iron and steel, and the coke production of Durham has declined relatively to that of Yorkshire, and the industry has appeared in Lincolnshire.

The Committee considers that an important cause of the shift southwards has been the exhaustion of the northern ores, which in 1924 supplied only onethird of the national output as compared with onehalf in 1913. In other industries, different, but no less potent, causes of migration have been at work, among which the Committee cites the greater freedom in the south from restraints due to hard-and-fast trade customs and the desire to obtain the full benefit from more economic organisation. Another probable cause which does not seem to have been directly considered by the Committee is the fact that local rates are generally lower in the south than in the north.

Further industrialisation of non-urban areas in the south of England will probably be stimulated by the development of electric power distribution and other forces, such as the development of road transport, making for de-centralisation. It would seem that now the process of concentration of industry in the north which commenced in the eighteenth century may be reversed, and a gradual though perhaps partial process of de-centralisation substituted.

\title{
Tobacco Culture.
}

TOBACCO is no exception to the rule that plants require phosphorus for growth, but it needs little compared with other crops. Under certain conditions, the growers may profitably take advantage of this property. Field tests have been carried out at Windsor, U.S.A. (Report for 1926 of the Connecticut Agricultural Experiment Station), on old tobacco land which has carried the same crop for a long period of years regularly manured with a complete fertiliser. On such land, no response to phosphorus treatment was obtained, neither the yield, quality, nor burning properties of the tobacco being affected by withholding the application. This is considered due to the fact that, as so little phosphorus is taken up by the crop, and only a small quantity removed by leaching, a surplus supply has been built up through the continued manurial treatment. Growers on this land can therefore effect considerable saving by omitting phosphate from their fertiliser mixtures for an indefinite number of years without incurring any risk, as the organic constituents of the manure applied are considered capable of supplying sufficient phosphorus to guard against depletion. However, on tobacco land where some rotation of crops is practised or on new fields, the same conditions do not obtain, and it would probably not be economic to omit the phosphatic dressings.

$$
\text { No. 3053, VoL. 121] }
$$

Experiments have also been carried out on the new Heber process of sweating tobacco recently developed in Germany. After the leaves are cured, a fermentation or sweating process is necessary before they are suitable for manufacture into cigars. The two methods in common use are the 'bulk' and 'case" processes. In the former, large piles of tobacco are allowed to heat up to $120^{\circ} \mathrm{F}$., then shaken out and repiled, the process being repeated a number of times and requiring three to six weeks. In the 'case' method the tobacco is tightly packed in wooden cases and kept artificially heated at about $100^{\circ} \mathrm{F}$. for six weeks or longer. The Heber process is applicable to either method, and consists in spraying the layers of tobacco, as the 'bulk' or ' case' is being made up, with a solution containing an 'active principle,' fermentation being by this means completed in eight days. In a control test where water was substituted for the solution, the tobacco was still very raw when the treated tobacco was completely fermented.

Besides the immense reduction in time and labour obtained by using this process, further advantages noticeable were that the leaves were lighter in colour and incurred less breakage and loss in weight. On other points, however, such as aroma and burning properties, no consistent differences were found between leaves sweated by the old or new processes. 